\title{
Decreased Levels of Serum Brain-Derived Neurotrophic Factor in Male Pediatric Patients with Depression
}

\author{
Tsuyoshi Sasaki*, ${ }^{*}$, Tomihisa Niitsu ${ }^{2}$, Tasuku Hashimoto ${ }^{3}$, Nobuhisa Kanahara ${ }^{3}$, Akihiro Shiina ${ }^{3}$, \\ Tadashi Hasegawa $^{3}$, Hiroshi Kimura ${ }^{3}$, Maki Ishikawa ${ }^{4}$,Junko Tone $^{1}$, Atsushi Yamauchi ${ }^{1}$, \\ Yutaka Hosoda ${ }^{1}$, Masaru Kunou ${ }^{5}$, Junpei Takahashi ${ }^{5}$, Tamaki Ishima ${ }^{6}$, Yuko Fujita ${ }^{6}$, \\ Michiko Nakazato ${ }^{1,2}$, Kenji Hashimoto ${ }^{6}$ and Masaomi Iyo ${ }^{1,3,6}$ \\ ${ }^{1}$ Department of Child Psychiatry, Chiba University Graduate School of Medicine, Inohana 1-8-1, Chiba, 260-8670, \\ Japan \\ ${ }^{2}$ Research Center for Child Mental Development, Chiba University Graduate School of Medicine Inohana 1-8-1, Chiba, \\ 260-8670, Japan \\ ${ }^{3}$ Department of Psychiatry, Chiba University Graduate School of Medicine, Inohana 1-8-1, Chiba, 260-8670, Japan \\ ${ }^{4}$ Chiba Psychiatric Medical Center, Toyosuna 5, Chiba 261-0024, Japan \\ ${ }^{5}$ Department of Child Psychiatry, Chiba Aoba Municipal Hospital, Aoba-Chou 1273-2, Chiba 260-0852, Japan \\ ${ }^{6}$ Division of Clinical Neuroscience, Chiba University Center for Forensic Mental Health, 1-8-1 Inohana, Chiba \\ 260-8670, Japan
}

\begin{abstract}
Background: Brain-derived neurotrophic factor (BDNF) plays an important role in the pathophysiology of major depressive disorder (MDD). Several meta-analyses have shown decreased serum levels of BDNF in adult patients with MDD, but there has been no report on the serum levels of BDNF in pediatric patients with depression. In this study, we investigated whether serum levels of BDNF are altered in pediatric patients with depression.

Methods: We measured serum BDNF levels in the following four groups: male pediatric patients with depression $(\mathrm{n}=13)$, female pediatric patients with depression $(n=17)$, and age-matched normal control subjects $(n=10$ for Male, $n=12$ for Female). Patients were evaluated using the Children's Depression Rating Scale Revised (CDRS-R). Serum levels of BDNF were measured with the sandwich ELISA method.

Results: Serum levels $(6.97 \pm 3.69 \mathrm{ng} / \mathrm{mL}$ [mean $\pm \mathrm{SD}$ ] $)$ of BDNF in male pediatric patients with depression were significantly ( $\mathrm{p}=0.019)$ lower than those $(10.67 \pm 3.11 \mathrm{ng} / \mathrm{mL})$ in the male control group. However, there was no difference between the female pediatric patients with depression $(9.29 \pm 4.61 \mathrm{ng} / \mathrm{mL})$ and the female control group $(10.21 \pm 4.79$ $\mathrm{ng} / \mathrm{mL}$ ). Furthermore, there was no correlation between serum levels of BDNF and CDRS-R scores in the pediatric patients with depression. Interestingly, there was a significant negative correlation $(r=-0.683, p=0.010)$ between the serum BDNF levels and the duration of illness in male, but not female, pediatric patients with depression.

Conclusions: This study suggests that low BDNF levels may play a role in the pathophysiology of male pediatric patients with depression.
\end{abstract}

Keywords: Biomarker, Brain-derived neurotrophic factor (BDNF), Pediatric depression, Serum.

\section{INTRODUCTION}

Major depressive disorder (MDD) is a serious disorder that affects approximately $17 \%$ of the population at some point in life, resulting in major social and economic consequences [1-3]. MDD in children and adolescents is characterized by one or more major depressive episodes, defined as at least 2 weeks of persistent change in mood manifested by either depressed or irritable mood or loss of interest or

*Address correspondence to this author at the Department of Child Psychiatry, Chiba University Graduate School of Medicine, Inohana 1-8-1, Chiba, 260-8670, Japan; Tel: +81-43-226-2297; Fax: +81-43-226-2297;

E-mail: sasaki@ faculty.chiba-u.jp pleasure and at least four additional symptoms of depression [4]. Depression in children has been reported to be a common, recurrent and impairing condition associated with increased psychosocial and medical morbidity and mortality [5]. The prevalence of depression in children and in adolescences is $1-2 \%$ and $3-8 \%$, respectively [6]. Depressive symptoms are also associated with significant functional impairments in school and work, frequent legal involvement [5-9], and increased risk for substance abuse and completed suicide [10-13]. However, the precise neurobiological mechanisms underlying the pathophysiology of pediatric depression are currently unknown. One way to combat this disorder would be to discover novel biomarkers for it. Identification of bio- 
markers would aid both in the diagnosis of this disorder, and in the development of effective psychiatric medications to treat it [14-18].

Multiple lines of evidence suggest that brain-derived neurotrophic factor (BDNF) plays an important role in the pathophysiology of MDD, as well as in the mechanisms underlying the therapeutic actions of antidepressants [18-23]. Our group reported that serum BDNF levels were significantly lower in adult patients with MDD and eating disorders (anorexia nervosa and bulimia nervosa) than in healthy controls [24-25]. And that serum BDNF levels in adult patients with MDD were significantly increased after antidepressant treatment [24]. Four subsequent meta-analyses confirmed our findings [24, 26-29]. Therefore, it is likely that the measurement of blood BDNF levels would be a potential biomarker for MDD [18]. However, there has been no report demonstrating the blood levels of BDNF in pediatric patients with depression.

In this study, we examined whether serum levels of $\mathrm{BDNF}$ are altered in pediatric patients with depression. It has previously been reported that girls have twice the risk of developing depression after the onset of puberty compared to boys [30], and that a group of adolescent females scored lower on personal resilience and showed more depressive symptoms than adolescent males [31]. Therefore, to address this potential difference between sexes, we performed our analysis separately in male and female pediatric patients.

\section{METHODS AND MATERIALS}

\subsection{Patients}

Thirteen male patients with pediatric depression (age: 13.0 years [SD 1.00]; range: 11-14 years) and 17 female patients with pediatric depression (age: 12.94 years [SD 1.85]; range: $8-15$ years) were recruited from Chiba University Hospital (Table 1). Age and ethnicity-matched healthy male pediatric subjects (age: 14.30 years [SD 2.80]; range: 9-17 years) and female pediatric subjects (age: 11.50 years [SD 3.71]; range: 7-17 years) also participated in this study as normal control subjects (Table 1). The ethics committee of Chiba University Graduate School of Medicine approved the study protocol, and all of the subjects provided written informed consent for participation in the study. All pediatric patients with depression (F32) were diagnosed according to the ICD-10 criteria [32], and were classified as having one of three subtypes (Mild Depressive Episode type [ $n=5]$, Moderate Depressive Episode type [ $n=21]$ or Severe Depressive Episode type $[n=4])$. All subjects completed the Children's Depression Rating Scale-Revised (CDRS-R). The CDRS-R was used to measure children's depressive symptomatology [33]. The durations of illness in the male patients with pediatric depression and female patients with pediatric depression were $12.08 \pm 10.95$ months and $10.06 \pm 10.6$ months, respectively (Table 1). The antidepressants administered for treatment were milnaciplan $(25-125 \mathrm{mg} /$ day; $n=4)$, fluvoxamine (50-100 mg/day; $n=3$ ), sulpiride (50-100 mg/day; $n$ $=3)$, and perospirone $(4 \mathrm{mg} / \mathrm{day} ; n=1)$. Nineteen of the patients were drug-naive. Healthy controls were recruited from Chiba-City by advertisement. All control group participants underwent a comprehensive assessment of medical history to eliminate individuals with any neurological or other medical disorders. The Structured Clinical Interview MINI-KID [34] was also conducted in order to determine the existence of any personal or familial history of past or present mental illness. None of the control subjects initially recruited was found to fulfill these exclusion criteria.

\subsection{Procedures}

Serum samples from the patients and normal control subjects were collected between 10:00 to15:00, and were stored at $-80^{\circ} \mathrm{C}$ until they were used for the assay. Serum levels of BDNF were measured by using the BDNF Emax Immunoassay System kit (Promega, Madison, WI) according to the manufacturer's instructions. To minimize the assay variance, serum BDNF levels were measured in all subjects on the same day. Briefly, 96-well plates were coated with antiBDNF monoclonal antibody and incubated at $4{ }^{\circ} \mathrm{C}$ for 18 hours. The plates were then incubated in a blocking buffer for 1 hour at room temperature. Next, the samples and the BDNF standards were maintained at room temperature and shaken for 2 hours, followed by washing with the washing buffers. The plates were incubated with antihuman BDNF polyclonal antibody at room temperature for 2 hours, washed, and incubated with anti-immunoglobulin Y antibody conjugated to horseradish peroxidase for 1 hour at

Table 1. Demographic Characterization of Patients with Pediatric Depression and Normal Controls

\begin{tabular}{|c|c|c|c|c|c|c|}
\hline & Male & Male & & Female & Female & \\
\hline $\begin{array}{l}\text { Duration of illness } \\
\text { (months) }\end{array}$ & - & $\begin{array}{c}12.08 \pm 10.95 \\
(1-36)\end{array}$ & - & - & $\begin{array}{c}10.06 \pm 10.60 \\
(1-39)\end{array}$ & - \\
\hline CDRS-R Score & - & $\begin{array}{c}56.08 \pm 20.46 \\
(27-97)\end{array}$ & - & - & $55.29 \pm 13.50(35-84)$ & - \\
\hline BDNF (ng/mL) & $10.67 \pm 3.11$ & $6.97 \pm 3.69$ & $0.0187^{*}$ & $10.21 \pm 4.79$ & $9.29 \pm 4.61$ & 0.6089 \\
\hline
\end{tabular}

Values are the mean $\pm \mathrm{SD}$. Values in parenthesis are the range.

BDNF: brain-derived neurotrophic factor. CDRS-R: Children's Depression Rating Scale-Revised.

Statistical analysis was performed by Student's $t$-test. *Statistically significant at $\mathrm{p}<0.05$. 

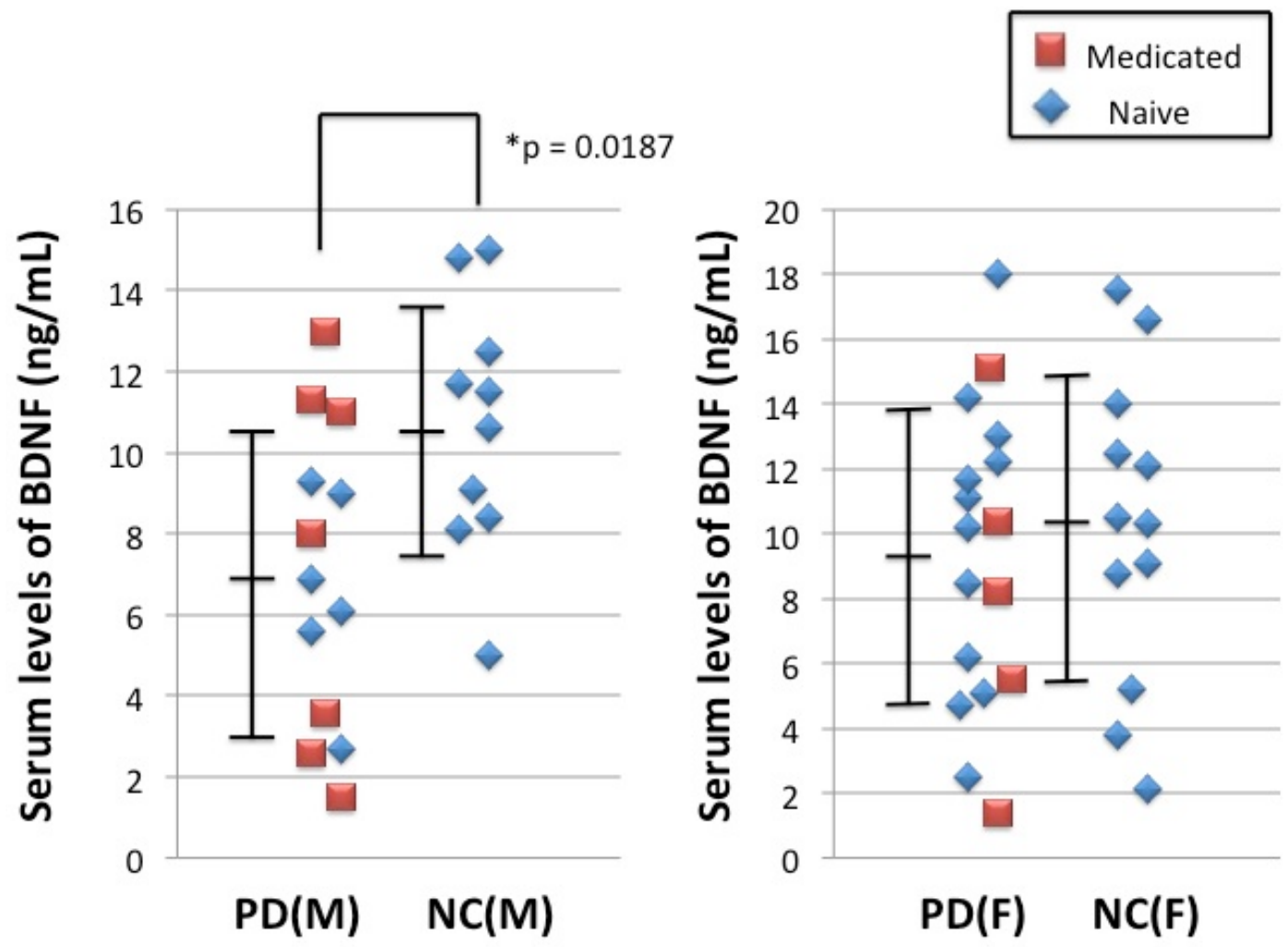

Fig. (1). Serum levels of BDNF in pediatric patients with depression (PD) and normal controls (NC). The blue diamonds represent drug naïve patients, and the red squares represent medicated patients. Serum levels of BDNF in male (M) pediatric patients with depression (6.97 \pm $3.69 \mathrm{ng} / \mathrm{ml}$ ) were significantly $(\mathrm{t}=2.548, \mathrm{p}=0.019)$ lower than those of normal male controls $(10.67 \pm 3.11 \mathrm{ng} / \mathrm{ml})$. In contrast, serum levels of $\mathrm{BDNF}$ in female $(\mathrm{F})$ pediatric patients with depression $(9.29 \pm 4.61 \mathrm{ng} / \mathrm{ml})$ were not different $(\mathrm{t}=1.544$, $\mathrm{p}=0.609)$ from those of normal female controls $(10.21 \pm 4.79 \mathrm{ng} / \mathrm{ml})$.

room temperature. Finally, an incubation in peroxidase substrate and tetramethylbenzidine solution was conducted to produce a color reaction. The reaction was stopped with 1 $\mathrm{mol} / \mathrm{L}$ hydrochloric acid and absorbance at $450 \mathrm{~nm}$ was measured with an automated microplate reader (Emax; Molecular Devices, Sunnyvale, CA).

\subsection{Statistical Analysis}

The data were presented as the mean \pm standard deviation (S.D.). The statistical analysis of the two groups was performed using Student's $t$-test. The relationship between two variables was ascertained using Pearson's correlation coefficients. Values of $p<0.05$ were considered statistically significant.

\section{RESULTS}

Serum levels of BDNF in male pediatric patients with depression $(6.97 \pm 3.69 \mathrm{ng} / \mathrm{ml})$ were significantly $(\mathrm{t}=2.548$, $\mathrm{p}=0.019)$ lower than those of healthy male controls $(10.67 \pm$ $3.11 \mathrm{ng} / \mathrm{ml})$. However, there was no difference among the drug-naive group $(n=6)$, medicated group $(n=7)$, and control group $(n=10)$. There was also no correlation between serum levels of BDNF and CDRS-R scores in male patients. Interestingly, there was a significant negative correlation $(\mathrm{r}=$ 0.683, $\mathrm{p}=0.010$ ) between the serum BDNF levels and the duration of illness in male pediatric patients with depression (Fig. 2).
Serum levels of BDNF in female pediatric patients with depression $(9.29 \pm 4.61 \mathrm{ng} / \mathrm{ml})$ were not different $(\mathrm{t}=1.544$, $\mathrm{p}=0.609)$ from those of healthy female controls $(10.21 \pm 4.79$ $\mathrm{ng} / \mathrm{ml}$ ) (Table 1 and Fig. 1). There was no difference among the drug-naive group $(n=12)$, medicated group $(n=5)$, and control group $(n=12)$. There was no correlation between serum levels of BDNF and CDRS-R scores in female patients.

\section{DISCUSSION}

In this study, we found that serum BDNF levels in male pediatric patients with depression were significantly lower than those of age-matched normal male controls. To the best of our knowledge, this is the first report demonstrating decreased serum levels of BDNF in male, but not female, pediatric patients with depression. Very recently, Pandey et al. [35] reported that the levels of BDNF mRNA in the lymphocytes were significantly decreased in a group of pediatric depressed patients compared with age-matched normal controls, and that the levels of BDNF protein in the cytosol fraction of platelets were significantly decreased in the pediatric depressed patients compared with normal controls. Furthermore, the levels of BDNF in the cytosol fraction of platelets from drug-free, male pediatric patients with depression were significantly lower than those of age-matched normal controls [35], consistent with our data on male pediatric patients with depression. However, the BDNF protein levels in the cytosol fraction of platelets obtained from female pediatric patients with depression were also significantly decreased 


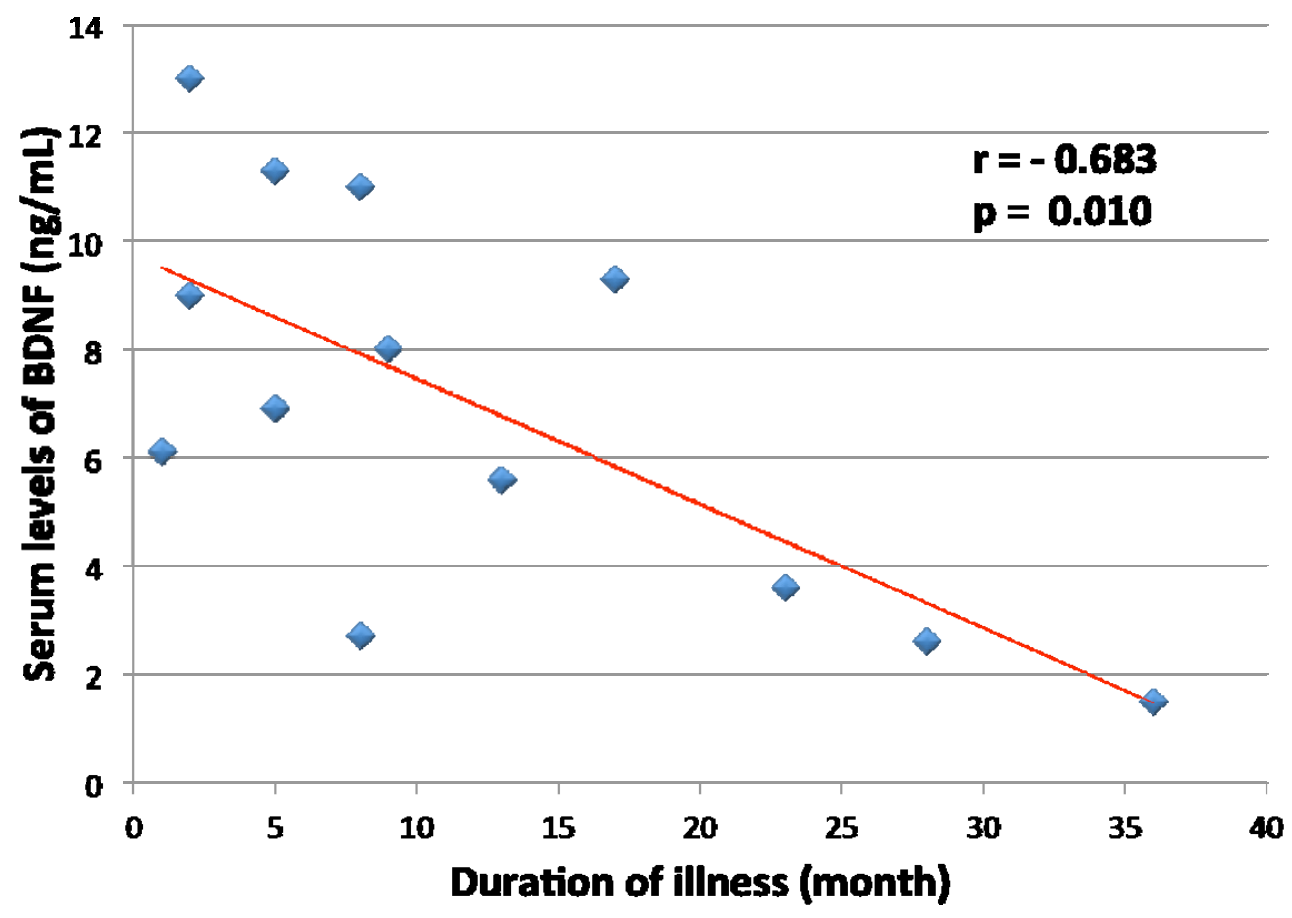

Fig. (2). Relationship between the serum levels of BDNF and the duration of illness in male pediatric subjects with depression. There was a significant negative correlation $(r=-0.683, p=0.010)$ between the serum levels of BDNF and the duration of illness in male pediatric patients $(\mathrm{n}=13)$ with depression.

compared with normal controls in this previous study [35], which was not consistent with our study. The reasons for this discrepancy are currently unknown. One possibility may be that the disparate results were attributable to the difference in the race of the subjects enrolled. That is, in the study by Pandey et al. [35] there were Asian, black, Hispanic, and white control and depressed patients, whereas in our study all the subjects were Japanese. Another possible cause was the difference in the source of blood sample (serum vs. platelets). Clearly, a further study using a large sample size will be needed to resolve the discrepancy.

In this study, unlike in male subjects, we did not find any difference of serum BDNF levels between female pediatric patients with depression and female control subjects. The reasons underlying this gender difference are unknown. It is well known that prior to puberty the prevalence of depression is roughly equal in both sexes, but from puberty onwards, depression is more common in females [36], indicating a gender difference in pediatric depression. Therefore, it is likely that biological, hormonal, and psychosocial changes in female subjects contribute to the gender difference, although a further detailed study will be needed to confirm this idea.

It has also been reported that blood levels of BDNF are decreased in adult patients with bipolar disorders (BPD) during manic, depressed and even euthymic states, although these findings were not replicated in other reports [18]. A recent meta-analysis study demonstrated that patients with BPD had lower levels of BDNF than healthy controls [37]. In addition, BDNF levels were significantly increased after the pharmacological treatment of the manic state. These findings indicate that BDNF levels are abnormally reduced in manic and depressed states of BPD, and that the reduced level in the manic state increases after pharmacological treatment. There is a possibility that onset of BPD or schizophrenia will occur in some children with depression. It may therefore be of interest to measure serum BDNF levels in children with and without depression in order to determine the role of BDNF as a serological marker in children who later develop BPD or schizophrenia.

In this study, we found a significant negative correlation $(r=-0.683, p=0.010)$ between the serum levels of BDNF and the duration of illness in male pediatric patients with depression. It should be noted that serum BDNF levels are negatively related with the duration of illness, since longstanding depression in adolescence is a powerful predictor of continued mental health problems in adulthood [38].

The main limitation of this study is the small sample size (male patient $\mathrm{n}=13$, female patient $\mathrm{n}=17$ ). Therefore, a further study using a large sample size will be necessary. Another limitation of this study may be the effects of medication since antidepressants could affect serum BDNF levels. Therefore, a further study using antidepressant-untreated patients will be also needed.

\section{CONCLUSION}

In conclusion, this study suggests that decreased levels of BDNF may play a role in the pathophysiology of male patients with pediatric depression, although a further study using a large sample size will be needed.

\section{ABBREVIATIONS \\ $\mathrm{BDNF}=$ Brain-derived neurotrophic factor \\ $\mathrm{BPD}=$ Bipolar disorders}


$\mathrm{MDD}=$ Major depressive disorder

CDRS-R = Children's Depression Rating Scale Revised

\section{REFERENCES}

[1] Kessler, R.C.; McGonagle, K.A.; Zhao, S.; Nelson, C.B.; Hughes, M.; Eshleman, S.; Wittchen, H.U.; Kendler, K.S. Lifetime and 12month prevalence of DSM-III-R psychiatric disorders in the United States. Results from the National Comorbidity Survey. Arch. Gen. Psychiatry, 1994, 5, 8-19.

[2] Hirschfeld, R.M.; Weissman, M.M. Risk factors for major depression and bipolar disorder. In: Davis, K.L.; Charney, D.; Coyle, J.T.; Nemeroff, C.; Eds. Neuropsychopharmacology - The Fifth Generation of Progress. Lippincott Williams \& Wilkins, Philadelphia, USA 2002; 1017-25.

[3] Belmaker, R.H.; Agam, G. Major depressive disorder. N. Eng. J. Med., 2008, 358, 55-68.

[4] American Psychiatric Association. Diagnostic and Statistical Manual of Mental Disorders, 4th ed. American Psychiatric Press: Washington, DC, 1994.

[5] Brent, D.A.; Maalouf, F.T. Pediatric depression: is there evidence to improve evidence-based treatments? J. Child. Psychol. Psychiatry, 2009, 50, 143-152.

[6] Fleming, J.E.; Offord, D.R. Epidemiology of childhood depressive disorders: a critical review. J. Am. Acad. Child. Adolesc. Psychiatry, 1990, 29(4), 571-80.

[7] Kandel, D.B.; Davies, M. Adult sequelae of adolescent depressive symptoms. Arch. Gen. Psychiatry, 1986, 43(3), 255-262.

[8] Kovacs, M.; Feinberg, T.L.; Crouse-Novak, M.A.; Paulauskas, S.L.; Finkelstein, R. Depressive disorders in childhood. I. A longitudinal prospective study of characteristics and recovery. Arch. Gen. Psychiatry, 1984, 41(3), 229-237.

[9] Pfeffer, C.R.; Klerman, G.L.; Hurt, S.W.; Lesser, M.; Peskin, J.R.; Siefker, C.A. Suicidal children grow up: demographic and clinical risk factors for adolescent suicide attempts. J. Am. Acad. Child. Adolesc. Psychiatry, 1991; 30(4), 609-616.

[10] Birmaher, B.; Ryan, N.D.; Williamson, D.E.; Brent, D.A.; Kaufman, J. Childhood and adolescent depression: a review of the past 10 years. Part II. J. Am. Acad. Child. Adolesc. Psychiatry, 1996, 35(12), 1575-1583.

[11] Birmaher, B.; Brent, D.; AACAP Work Group on Quality Issues; Bernet, W.; Bukstein, O.; Walter, H.; Benson, R.S.; Chrisman, A.; Farchione, T.; Greenhill, L.; Hamilton, J.; Keable, H.; Kinlan, J.; Schoettle, U.; Stock, S.; Ptakowski, K.K.; Medicus, J. Practice parameter for the assessment and treatment of children and adolescents with depressive disorders. J. Am. Acad. Child. Adolesc. Psychiatry, 2007, 46(11), 1503-1526.

[12] Brent, D.A. Correlates of the medical lethality of suicide attempts in children and adolescents. J. Am. Acad. Child. Adolesc. Psychiatry, 1987, 26(1), 87-91.

[13] Maalouf, F.T.; Brent, D.A. Pharmacotherapy and psychotherapy of pediatric depression. Expert Opin. Pharmacother., 2010, 11, 21292140 .

[14] Ising, M.; Horsmann, S.; Kloiber, S.; Lucae, S.; Binder, E.B.; Kern, N.; Künzel, H.E.; Pfennig, A.; Uhr, M.; Holsboer, F. Combined dexamethasone/corticotrophin releasing hormone test predicts treatment response in major depression - a potential biomarker. Biol. Psychiatry, 2007, 62, 47-54.

[15] Miller, A.H.; Maletic, V.; Raison, C.L. Inflammation and its discontents: the role of cytokines in the pathophysiology of major depression. Biol. Psychiatry, 2009, 65, 732-741.

[16] Lakhan, S.E.; Vieira, K.; Hamlat, E. Biomarkers in psychiatry: Drawbacks and potential for misuse. Int. Arch. Med., 2010, $3,1$.

[17] Domenici, E.; Wille, D.R.; Tozzi, F.; Prokopenko, I.; Miller, S.; McKeown, A.; Brittain, C.; Rujescu, D.; Giegling, I.; Turck, C.W.; Holsboer, F.; Bullmore, E.T.; Middleton, L.; Merlo-Pich, E.; Alexander, R.C.; Muglia, P. Plasma protein biomarkers for depression and schizophrenia by multi analyte profiling of case-control collections. PLOS ONE 2010, 5, e9166.

[18] Hashimoto K. Brain-derived neurotrophic factor as a biomarker for mood disorders: an historical overview and future directions. Psychiatry Clin. Neurosci., 2010, 64(4), 341-357.

[19] Duman, R.S.; Heninger, G.R.; Nestler, E.J. A molecular and cellular theory of depression. Arch. Gen. Psychiatry., 1997, 54(7), 597606.

[20] Altar, C.A. Neurotrophins and depression. Trends Pharmacol. Sci., 1999, 20(2), 59-61.

[21] Nestler, E.J.; Gould, E.; Manji, H.K.; et al. Preclinical models: status of basic research in depression. Biol. Psychiatry, 2002, 52, 503-528.

[22] Hashimoto, K.; Shimizu, E.; Iyo, M. Critical role of brain-derived neurotrophic factor in mood disorders. Brain Res. Brain Res. Rev., 2004, 45(2), 104-114.

[23] Martinowich, K.; Manji, H.; Lu, B. New insights into BDNF function in depression and anxiety. Nat. Neurosci., 2007, 10(9), 10891093.

[24] Shimizu, E.; Hashimoto, K.; Okamura, N.; Koike, K.; Komatsu, N.; Kumakiri, C.; Nakazato, M.; Watanabe, H.; Shinoda, N.; Okada, S.; Iyo, M. Alterations of serum levels of brain-derived neurotrophic factor (BDNF) in depressed patients with or without antidepressants. Biol. Psychiatry, 2003, 54(1), 70-75.

[25] Nakazato, M.; Hashimoto, K.; Shimizu, E.; Kumakiri, C.; Koizumi, H.; Okamura, N.; Mitsumori, M.; Komatsu, N.; Iyo, M. Decreased levels of serum brain-derived neurotrophic factor in female patients with eating disorders. Biol. Psychiatry., 2003, 54(4), 485-490.

[26] Sen, S.; Duman, R.; Sanacora, G. Serum brain-derived neurotrophic factor, depression, and antidepressant medications: metaanalyses and implications. Biol. Psychiatry, 2008, 64(6), 527-532.

[27] Brunoni, A.R.; Lopes, M.; Fregni, F. A systematic review and meta-analysis of clinical studies on major depression and BDNF levels: implications for the role of neuroplasticity in depression. Int. J. Neuropsychopharmacol., 2008, 11(8), 1169-1180.

[28] Bocchio-Chiavetto, L.; Bagnardi, V.; Zanardini, R.; Molteni, R.; Nielsen, M.G.; Placentino, A.; Giovannini, C.; Rillosi, L.; Ventriglia, M.; Riva, M.A.; Gennarelli, M. Serum and plasma BDNF levels in major depression: a replication study and meta-analyses. World J. Biol. Psychiatry, 2010, 11(6), 763-773.

[29] Molendijk, M.L.; Bus, B.A.; Spinhoven, P.; Penninx, B.W.; Kenis, G.; Prickaerts, J.; Voshaar, R.O.; Elzinga, B.M. Serum levels of brain-derived neurotrophic factor in major depressive disorder: state-trait issues, clinical features and pharmacological treatment. Mol. Psychiatry, 2010.

[30] Lewinsohn, P.M.; Rohde, P.; Seeley, J.R. Major depressive disorder in older adolescents: prevalence, risk factors, and clinical implications. Clin. Psychol. Rev., 1998, 18(7), 765-794.

[31] Hänninen V, Aro H. Sex differences in coping and depression among young adults. Soc. Sci. Med., 1996, 43(10), 1453-1460.

[32] World Health Organization. The ICD-10 Classification of Mental and Behavioural Disorders: Clinical Descriptions and Diagnostic Guidelines.

[33] Poznanski, E.O.; Grossman, J.A.; Buchsbaum,Y.; Banegas, M.; Freeman, L.; Gibbons, R. Preliminary studies of the reliability and validity of the children's depression rating scale. J. Am. Acad. Child. Psychiatry, 1984, 23, 191-197.

[34] Sheehan, D.V.; Sheehan, K.H.; Shytle, R.D.; Janavs, J.; Bannon, Y.; Rogers, J.E.; Milo, K.M.; Stock, S.L.; Wilkinson, B. Reliability and validity of the Mini International Neuropsychiatric Interview for Children and Adolescents (MINI-KID). J. Clin. Psychiatry, 2010, $71(3), 313-326$.

[35] Pandey, G.N.; Dwivedi, Y.; Rizavi, H.S.; Ren, X.; Zhang, H.; Pavuluri, M.N. Brain-derived neurotrophic factor gene and protein expression in pediatric and adult depressed subjects. Prog. Neuropsychopharmacol. Biol. Psychiatry, 2010, 34(4), 645-651.

[36] Park, R.J.; Goodyer, I.M. Clinical guidelines for depressive disorders in childhood and adolescence. Eur. Child. Adolesc. Psychiatry, 2000, 9(3), 147-161. 
[37] Lin, P.Y. State-dependent decrease in levels of brainderived neurotrophic factor in bipolar disorder: a metaanalytic study. Neurosci. Lett., 2009, 466, 139-143.
[38] Jonsson, U.; Bohman, H.; von Knorring, L.; Olsson, G.; Paaren, A.; von Knorring, A.L. Mental health outcome of long-term and episodic adolescent depression: 15-year follow-up of a community sample. J. Affect. Disord., 2011, 130(3), 395-404.

(C) Sasaki et al.; Licensee Bentham Open.

This is an open access article licensed under the terms of the Creative Commons Attribution Non-Commercial License (http://creativecommons.org/licenses/ by-nc/3.0/) which permits unrestricted, non-commercial use, distribution and reproduction in any medium, provided the work is properly cited. 